\title{
HUBUNGAN PELAKSANAAN RANGE OF MOTION DENGAN RISIKO DEKUBITUS PADA PASIEN STROKE
}

\author{
Insana Maria \\ Staff Dosen Sekolah Tinggi Kesehatan Intan Martapura, 71213, Indonesia \\ Email : maria.insana82@gmail.com
}

\begin{abstract}
ABSTRAK
Latar Belakang : Stroke merupakan pembunuh nomor 3 setelah penyakit jantung dan kanker, stroke biasanya ditandai dengan kelumpuhan anggota gerak pada salah satu sisi anggota tubuh, penatalaksanaan yang dapat dilakukan pada penderita stroke salah satunya yaitu Range Of Motion. Terapi Range Of Motion merupakan salah satu terapi yang membantu memulihkan keadaan penderita stroke yang mengalami kelumpuhan, serta dilakukannya Range Of Motion agar tidak terjadinya risiko dekubitus. Penelitian bertujuan untuk mengetahui Hubungan Pelaksanaan Range Of Motion dengan Risiko Dekubitus Pada Pasien Stroke.

Metode : Penelitian ini menggunakan metode analitik dengan desain penelitian korelasi, penelitian dilaksanakan di Ruang Saraf Rumah Sakit Ratu Zalecha Martapura jumlah populasi pasien stroke sebanyak 168 orang dan sampel sebanyak 118 orang dengan teknik sampling Consecutive Sampling, Instrumen berupa kuesioner dan teknik analisis data menggunakan uji Spearman's.

Hasil : Hasil dari penelitian ini dengan menggunakan uji Spearman's diperoleh nilai $p=$ 0,000 yang berarti $\mathrm{H} 0$ ditolak dan $\mathrm{Ha}$ diterima, yang artinya ada hubungan antara pelaksanaan range of motion dengan risiko dekubitus pada pasien stroke di ruang saraf RSUD Ratu Zalecha Martapura.

Kesimpulan: ada hubungan (significant) antara pelaksanaan range of motion dengan risiko dekubitus pada pasien stroke di ruang saraf RSUD Ratu Zalecha Martapura 2018 dan diharapkan penelitian ini mengoptimalkan latihan rentang gerak pada pasien stroke, karena dengan melaksanakan Range Of Motion dengan baik maka pasien dapat bergerak secara aktif maupun pasif agar terhindar dari risiko dekubitus.
\end{abstract}

Kata Kunci : Range Of Motion, Stroke, Dekubitus 


\section{PENDAHULUAN}

Era globalisasi menuntut manusia untuk hidup secara modern, praktis, cepat dan otomatis. Manusia telah dimanja oleh alat-alat canggih sehingga mengubah kebiasaan dan gaya hidup. Perubahanperubahan tersebut ternyata memiliki dampak negatif bagi kesehatan manusia, seperti kegemukan dan hipertensi. Keduanya merupakan pemicu timbulnya penyakit yang saat ini menjadi penyebab kecacatan tertinggi di dunia dengan posisi sebagai penyakit mematikan ketiga setelah penyakit jantung dan kanker. Penyakit ini lebih dikenal dengan sebutan stroke (Dinata CA, 2013).

Stroke biasanya ditandai dengan kelumpuhan anggota gerak pada salah satu sisi anggota tubuh. Penanganan yang optimal untuk penderita stroke merupakan peran utama perawat. Terapi Range Of Motion merupakan salah satu terapi yang dapat membantu memulihkan keadaan penderita stroke yang mengalami kelumpuhan. Penderita stroke dengan kelemahan anggota gerak dan sendi pada umumnya mengalami ketergantungan dalam pemenuhan kebutuhan fisik, dan berisiko mengalami kecacatan apabila tidak dilakukan rehabilitasi medik Range Of Motion secara teratur. Latihan (exercise) pada penderita stroke sangatlah penting selain terapi farmakologis dan terapi dengan modalitas alat, bahkan boleh dikatakan merupakan yang terpenting dari yang lain. Sesaat setelah seseorang mengalami stroke, ia akan mengalami kelumpuhan pada satu sisi badan. Apabila hal ini tidak ditanggulangi secara baik dan benar, akan menimbulkan cacat funsional dari alat-alat gerak tubuh, dan lamakelamaan akan lumpuh secara total dan kaku (Asmadi, 2008)

Kehadiran seorang perawat dalam proses perawatan pasien Stroke sangatlah penting terutama perawat dapat berperan untuk memberikan pendidikan kesehatan kepada pasien terutama dengan memberikan kesehatan dengan memperhatikan perilaku caring dan comfort perawat kepada pasien. (Insana Maria, dkk. 2019)

Berdasarkan studi pendahuluan di RSUD Ratu Zalecha Martapura pada tanggal 15 Januari 2018 dari hasil wawancara terhadap 10 orang pasien, terdapat 7 dari 10 yang menderita stroke yang tidak melaksanakan range of motion. Tidakan yang dilakukan agar tidak terjadi risiko dekubitus pada pasien stroke harus dilakukan sedini mungkin dan terus menerus. Pemberian posisi yang benar sangatlah penting dengan sasaran utama pemeliharaan integritas kulit yang dapat mengurangi tekanan, membantu kesejajaan tubuh yang baik, dan mencegah neuropati 
komprehensif. Untuk meminimalkan terjadinya kecacatan pada penderita stroke, diperlukan penanganan yang cepat, tepat, dan cermat (Batticaca, Fransisca B. 2012.).

\section{METODE PENELITIAN}

Jenis Penelitian ini adalah penelitian analitik, yaitu suatu bentuk penelitian yang bertujuan untuk menguji hipotesis dan mengadakan interpretasi yang lebih mendalam mengenai hubungan antar variabel. Pendekatan yang digunakan adalah observasional yaitu pendekatan penelitian yang mana dalam pengumpulan data tanpa ada intervensi atau perlakuan pada populasi (Nursalam, 2013).

Tempat penelitian dilakukan di Rumah Sakit Ratu Zalecha Martapura, pada bulan Maret sampai dengan bulan Mei 2018. Populasi dalam penelitian ini adalah Pasien penderita Stroke Di Ruang Saraf RSUD Ratu Zalecha Martapura. Sampel yang dilakukan penelitian adalah sebagian dari keseluruhan obyek yang diteliti dan dianggap mewakili seluruh populasi (Setiadi, 2007). Sampel yang diambil menggunakan metode Consecutive Sampling, sampel pada penelitian ini berjumlah 118 responden. Kriteria inklusi dalam penelitian ini : Semua pasien penderita stroke di Ruang Saraf SUD Ratu Zalecha Martapura. Sedangkan kriteria ekslusinya: Pasien Stroke yang tidak sadarkan diri.
Instrumen penelitian yang digunakan dalam penelitian ini yaitu Kuesioner Dan lembar observasi sederhana, Prinsipprinsip dalam etika penelitian ini, yaitu : Informed Consent (lembar persetujuan), anonymity (tanpa nama), confidentiality (kerahasiaan). Data yang telah di kumpulkan selanjutnya dilakukan pengolahan melalui tahap : editing, coding, scoring. Analisa data dalam penelitian ini dilakukan melalui dua tahap, yaitu analisis univariat dengan pengumpulan data berupa tabel distribusi frekuensi dan analisis bivariate menggunakan uji Chi Square.

\section{HASIL PENELITIAN}

Hasil Karakteristik Responden

Tabel 1

Distribusi Frekuensi Berdasarkan umur

\begin{tabular}{|c|c|c|c|}
\hline \multirow{2}{*}{ No. } & \multirow{2}{*}{ Umur } & \multicolumn{2}{|c|}{ Jumlah } \\
\cline { 3 - 4 } & & $\mathrm{F}$ & $(\%)$ \\
\hline 1. & $<20$ Tahun & 1 & 6 \\
\hline 2. & $21-30$ Tahun & 8 & 8 \\
\hline 3. & $31-40$ Tahun & 55 & 47 \\
\hline 4. & $>50$ Tahun & 54 & 46 \\
\hline & Jumlah & 118 & 100 \\
\hline
\end{tabular}

Sumber : Data primer yang dibuat (2018)

\section{Tabel 2}

\section{Distribusi Frekuensi Berdasarkan jenis}

\section{kelamin}

\begin{tabular}{|c|c|c|c|}
\hline No. & Jenis Kelamin & $\mathrm{F}$ & $(\%)$ \\
\hline 1. & Laki-Laki & 44 & 37 \\
\hline 2. & Perempuan & 74 & 63 \\
\hline & Jumlah & 118 & 100 \\
\hline
\end{tabular}

Sumber: Data primer yang dibuat (2018) 
Hasil Analisis Univariate

Tabel 3

Distribusi Frekuensi Lama Dirawat di Ruang Saraf RSUD Ratu Zalecha Martapura

\begin{tabular}{|c|c|c|c|}
\hline No. & Lama dirawat & $\mathrm{F}$ & $(\%)$ \\
\hline 1. & 1-3 Hari & 52 & 44 \\
\hline 2. & 4-6 Hari & 55 & 47 \\
\hline 3. & 7-10 Hari & 10 & 13 \\
\hline 4. & 11-13 Hari & 1 & 3 \\
\hline & Jumlah & 118 & 100 \\
\hline
\end{tabular}

Sumber: Data primer yang dibuat (2018)

Tabel 4

Distribusi Frekuensi Berdasarkan Skala Otot pada pasien Stroke di Ruang Saraf RSUD Ratu Zalecha Martapura

\begin{tabular}{|c|c|c|c|c|c|}
\hline \multirow{2}{*}{ No. } & \multirow{2}{*}{ Skala Otot } & \multicolumn{2}{|c|}{ Tangan } & \multicolumn{2}{|c|}{ Kaki } \\
\hline & & Kanan & Kiri & Kanan & Kiri \\
\hline 1. & $\begin{array}{c}\text { Tidak ada } \\
\text { pergerakan } \\
\text { Otot }\end{array}$ & $\begin{array}{c}5 \\
(4,2 \%)\end{array}$ & $\begin{array}{c}4 \\
(3,4 \%)\end{array}$ & $\begin{array}{c}5 \\
(4,2 \%)\end{array}$ & $\begin{array}{c}4 \\
(3,4 \%)\end{array}$ \\
\hline 2. & $\begin{array}{c}\text { Pergerakan } \\
\text { otot dapat } \\
\text { terlihat } \\
\text { namun } \\
\text { tidak ada } \\
\text { pergerakan } \\
\text { sendi }\end{array}$ & $\begin{array}{c}12 \\
(10,2 \%)\end{array}$ & $\begin{array}{c}31 \\
(26,3 \%)\end{array}$ & $\begin{array}{c}32 \\
(27,1 \%)\end{array}$ & $\begin{array}{c}58 \\
(49,2 \%)\end{array}$ \\
\hline 3. & $\begin{array}{l}\text { pergerakan } \\
\text { sendi } \\
\text { namun } \\
\text { tidak dapat } \\
\text { melawan } \\
\text { gravitasi }\end{array}$ & $\begin{array}{c}51 \\
(43,2 \%)\end{array}$ & $\begin{array}{c}43 \\
(63,4 \%)\end{array}$ & $\begin{array}{c}77 \\
(65,3 \%)\end{array}$ & $\begin{array}{c}39 \\
(33,1 \%)\end{array}$ \\
\hline 4. & $\begin{array}{c}\text { Pergerakan } \\
\text { melawan } \\
\text { gravitasi } \\
\text { namun } \\
\text { tidak } \\
\text { melawan } \\
\text { tahanan } \\
\end{array}$ & $\begin{array}{c}50 \\
(42,4 \%)\end{array}$ & $\begin{array}{c}40 \\
(33,9 \%)\end{array}$ & $\begin{array}{c}4 \\
(3,4 \%)\end{array}$ & $\begin{array}{c}5 \\
(4,2 \%)\end{array}$ \\
\hline & Jumlah & & & & \\
\hline
\end{tabular}

Sumber: Data primer yang dibuat (2018)

Tabel 5

Distribusi Frekuensi Pelaksanaan Range of Motion pada pasien Stroke di Ruang Saraf RSUD Ratu Zalecha Martapura

\begin{tabular}{|c|c|c|c|}
\hline No. & $\begin{array}{c}\text { Range of } \\
\text { Motion }\end{array}$ & F & $(\%)$ \\
\hline 1. & Dilakukan & 54 & 46 \\
\hline 2. & $\begin{array}{c}\text { Tidak } \\
\text { Dilakukan } \\
\text { Jumlah }\end{array}$ & 64 & 54 \\
\hline \multicolumn{3}{|c|}{ Sumber : Data primer yang dibuat (2018) }
\end{tabular}

Tabel 6

Distribusi Frekuensi Resiko Decubitus

Pada Pasien Stroke di Ruang Saraf RSUD Ratu Zalecha Martapura

\begin{tabular}{|c|c|c|c|}
\hline No. & $\begin{array}{c}\text { Range of } \\
\text { Motion }\end{array}$ & F & $(\%)$ \\
\hline 1. & Risiko Rendah & 35 & 30 \\
\hline 2. & Risiko Sedang & 50 & 43 \\
\hline 3. & Risiko Tinggi & 33 & 28 \\
\hline & Jumlah & 118 & 100 \\
\hline
\end{tabular}

Sumber: Data primer yang dibuat (2018)

\section{ANALISA BIVARIAT}

\section{Tabel 7}

Hubungan Pelaksanaan Range Of Motion Dengan Risiko Dekubitus Pada Pasien Stroke Di Ruang Saraf RSUD Ratu Zalecha Martapura Tahun 2018

\begin{tabular}{|c|c|c|c|c|c|}
\hline \multirow{2}{*}{$\begin{array}{c}\text { Range of } \\
\text { Motion }\end{array}$} & \multicolumn{3}{|c|}{ Resiko Decubitus } & & \\
\hline & Rendah & Sedang & Tinggi & & \\
\hline Dilakukan & $\begin{array}{c}25 \\
(21 \%)\end{array}$ & $\begin{array}{c}23 \\
(19 \%)\end{array}$ & $\begin{array}{c}6 \\
(5 \%)\end{array}$ & $\begin{array}{c}54 \\
(64 \%)\end{array}$ & \\
\hline $\begin{array}{c}\text { Tidak } \\
\text { Dilakukan }\end{array}$ & $\begin{array}{c}92 \\
86.8 \%\end{array}$ & $\begin{array}{c}0 \\
0.00 \%\end{array}$ & $\begin{array}{c}92 \\
86.8 \\
\end{array}$ & $\begin{array}{c}65 \\
(54 \%)\end{array}$ & \\
\hline \multicolumn{2}{|l|}{ Total } & $\begin{array}{c}35 \\
98.1 \%\end{array}$ & $\begin{array}{c}25 \\
(42 \%)\end{array}$ & $\begin{array}{c}33 \\
(28 \%) 0\end{array}$ & $\begin{array}{c}118 \\
(100 \\
\%\end{array}$ \\
\hline \multicolumn{6}{|c|}{$p=0,000 p<a(5 \%)$, Correlation Coefficient $(0,405)$} \\
\hline
\end{tabular}

\section{PEMBAHASAN}

Berdasarkan hasil Karakteristik responden pada tabel 1 yaitu mayoritas responden berusia 31-50 tahun sebanyak $57 \%$, diketahui penyakit stroke banyak menyerang pada usia produktif dikarenakan banyaknya kondisi perubahan gaya hidup yang tidak sehat. (Martini. 2019). Kemudian pada tabel 2 mayoritas jenis kelamin responden berjenis kelamin perempuan sebanyak $63 \%$ orang, adanya perbedaan yang bernakna antara jenis kelamin laki-laki dan perempuan, pasien stroke iskemik berjenis kelamin laki-laki 
memiliki keluaran klinis yang lebih baik dibandingkan jenis kelamin perempuan (Ignatius. 2017).

Hasil Univariate Tabel 3 mayoritas responden dirawat selama 4-6 hari yaitu sebanyak $47 \%$, penanganan awal pasien stroke akan sangat mempengaruhi lama dirawat di ruangan Rumah Sakit, lanjutan penanganan, perawatn dan pengobatan pasien stroke yang optimal akan meminimalkan proses hospitalisasi (Rusdiana. 2019). Berdasarkan tabel 4 mayoritas responden mengalami kelemahan pada kaki bagian kanan yaitu sebanyak $65 \%$, Seseorang yang mengalami stroke tidak melakukan range of motion dapat memperburuk keadaan pasien tersebut. Hal ini dikarenakan range of motion merupakan salah satu terapi yang dapat membantu memulihkan keadaan penderita stroke yang mengalami kelumpuhan. Penderita stroke dengan kelemahan anggota gerak dan sendi pada umumnya mengalami ketergantungan dalam pemenuhan kebutuhan fisik, dan berisiko mengalami kecacatan apabila tidak dilakukan rehabilitasi medik range of motion secara teratur (Susanti \& Difran. 2019).

Mayoritas pelaksanaan range of motion tidak dilakukan pada pasien stroke yaitu sebanyak 54\% terlihat pada tabel 5, kurangnya pelaksanaan Range of Motion pada pasien dapat memberikan dampak kurang baik pada pasien yaitu adanya resiko decubitus yang besar terjadi, seperti terlihat pada tabel 6 mayoritas pasien stroke di ruang saraf memiliki risiko sedang mengalami dekubitus yaitu sebanyak $42 \%$. apabila ini berlangsung lama, hal ini menyebabkan infusiensi aliran darah, anoksia atau iskemi jaringan dan akhirnya dapat mengakibatkan kematian sel. Oleh sebab itu pada pasien stroke kegiatan range of motion dan memindah posisi pasien sangat penting untuk di perhatiakan.

Hasil penelitian pada tabel 7 Sebanyak $46 \%$ pasien yang melakukan range of motion sebanyak $21 \%$ orang memiliki risiko rendah mengalami dekubitus, $19 \%$ orang memiliki risiko sedang mengalami dekubitus, dan $6(5 \%)$ orang memiliki risiko tinggi mengalami dekubitus, sedangkan dari 64 (54\%) pasien yang tidak melakukan range of motion sebanyak 10 $(8 \%)$ orang memiliki risiko rendah mengalami dekubitus, 27 (23\%) orang memiliki risiko sedang mengalami dekubitus, dan 33 (28\%) orang memiliki risiko tinggi mengalami dekubitus. Berdasarkan hasil uji statistik dengan menggunakan Uji Spearman's diperoleh nilai $\mathrm{p}=0,000$. Dengan nilai $\mathrm{p}<(\alpha=$ 0,05), maka H0 ditolak dan Ha diterima yang artinya ada hubungan (significant) antara pelaksanaan range of motion dengan risiko dekubitus pada pasien stroke 
di ruang saraf RSUD Ratu Zalecha Martapura 2018, sedangkan nilai correlation coefficient (koefisien korelasi) sebesar 0,405. Maka nilai ini menandakan hubungan yang korelasi sedang antara pelaksanaan range of motion dengan risiko dekubitus pada pasien stroke.

\section{KESIMPULAN}

Pelaksanaan range of motion pada pasien stroke berada pada kategori tidak dilakukan yaitu sebanyak 54\%. Resiko Dekubitus pada pasien stroke mayoritas berada pada kategori resiko sedang yaitu sebanyak 42\%. Berdasarkan hasil uji statistik dengan menggunakan Uji Spearman's diperoleh nilai $\mathrm{p}=0,000$. Dengan nilai $\mathrm{p}<(\alpha=0,05)$, maka $\mathrm{H} 0$ ditolak dan Ha diterima yang artinya ada hubungan (significant) antara pelaksanaan range of motion dengan risiko dekubitus pada pasien stroke di ruang saraf RSUD Ratu Zalecha Martapura 2018, sedangkan nilai correlation coefficient sebesar 0,405. Maka nilai ini menandakan hubungan yang korelasi sedang antara pelaksanaan range of motion dengan risiko dekubitus pada pasien stroke. Saran, diharapkan penelitian ini mengoptimalkan latihan rentang gerak pada pasien stroke, karena dengan melaksanakan Range Of Motion dengan baik maka pasien dapat bergerak secara aktif maupun pasif agar terhindar dari risiko dekubitus.

\section{AKNOWLEDMENT}

Terimakasih yang sebesarnya kami berikan kepada seluruh perasat dan dokter Ruang Saraf Rumah Sakit Ratu Zalecha Martapura karena telah di berikan kesempatan untuk melaksanakan penelitian pada pasien Stroke, selanjutnya terimakasih yang sebarnya bagi pimpinan STIKES Intan Martapura untuk dana penelitian yang telah di berikan.

\section{DAFTAR PUSTAKA}

Asmadi, 2008. Asuhan keperawatan Klien Dengan Gangguan Sistem Persarafan. Salemba Medika: Jakarta.

Batticaca, Fransisca B. 2012. Asuhan Keperawatan Pada Klien dengan Gangguan Sistem Persarafan. Jakarta: Salemba Medika.

Dinata CA, Safrita Y, Sastri S. 2013. Gambaran Faktor Risiko dan Tipe Stroke pada Pasien Rawat Inap di Bagian Penyakit Dalam RSUD Kabupaten Solok Selatan Periode 1 Januari 2010 - 31 Juni 2012. Jurnal Kesehatan Andalas. 2013;2(2). p. 57-61.

Dourman, 2013. Waspada Stroke usia Muda. Jakarta : Cerdas Sehat.

Ignatius dkk, 2017. Perbedaan jenis Kelamin sebagai faktor resiko terhadap keluaran klinis pasien stroke iskemik. Jurnal Kedokteran Diponegoro 6 (2) April 2017

Insana Maria, dkk. 2019. Perilaku Caring dan Comfort Perawat dalam 
Kegawatdaruratan. Deepublish.

Yogyakarta.

Martini. 2019. Hubungan Tingkat Pengetahuan Dengan Kepatuhan Diet Hipertensi Di Puskesmas Astambul. Jurnal Kesehatan Suaka Insan 4 (2) 2019

Rusdiana. 2019. Hubungan Kualitas Tidur Dengan Peningkatan Tekanan Darah Pada Pasien Hipertensi Di Wilayah Kerja Puskesmas Guntung Payung. Jurnal Kesehatan Suaka Insan 4 (2) 2019.

Susanti \& Difran. 2019. Pengaruh Range of Motion terhadap kekuatan otot pada Pasien Stroke. Jurnal Kesehatan Vokasional Vol. 4 No.2 Mei 2019 